\title{
KAJIAN PUSTAKA: INTEGRASI STEM UNTUK KETERAMPILAN ARGUMENTASI DALAM PEMBELAJARAN SAINS
}

\author{
Astrid Kinantya Paramita ${ }^{1}$ I Wayan Dasna ${ }^{1}$, Yahmin $^{1}$ \\ ${ }^{1}$ Jurusan Kimia FMIPA Universitas Negeri Malang, Jl. Semarang No. 5 Malang
}

\begin{abstract}
Abstrak - Peningkatan kualitas pembelajaran dengan menerapkan pembelajaran STEM sebagai suatu pendekatan preventif diharapkan mampu membantu siswa memaknai pembelajaran khususnya sains sehingga berimbas pada peningkatan keterampilan argumentasi. Pendekatan STEM disajikan sebagai jawaban atas tuntutan kebutuhan generasi berkualifikasi tinggi yang terfokus pada integrasi dari sains, teknologi, engineering dan matematika. Pengintegrasian STEM yang berkaitan dengan masalah kontekstual dianggap saling mendukung dengan pembelajaran sains yang memiliki relevansi dengan kehidupan. Namun dalam penerapannya, ditemukan variasi terkait pandangan tentang peran berbagai disiplin ilmu dalam pengintegrasian STEM. Hasil dari kajian literatur ini diharapkan berkontribusi pada rekomendasi penerapan pendekatan STEM dalam pembelajaran termasuk pada kebebasan untuk memahami dan menerapkan STEM di kelas bergantung pada kapasitas, kebutuhan, atau kenyamanan oleh guru maupun siswa.
\end{abstract}

Kata kunci: STEM, keterampilan argumentasi, pembelajaran sains.

\begin{abstract}
Improving the quality of learning by implementing STEM education as a preventive approach is expected to be able to help students interpret learning, especially science so that it impacts on improving argumentation skills. STEM is presented as an answer to the demands of the needs of highly qualified generations focused on the integration of science, technology, engineering and mathematics. The integration of STEM relating to contextual issues is considered mutually supportive with learning science that has relevance to life. But in its application, it was found variations related to views about the role of various scientific disciplines in the integration of STEM. The results of this literature review are expected to contribute to the recommendations for the application of STEM education in learning including the freedom to understand and apply STEM education in the classroom depending on the capacity, needs, or comfort of the teacher and students.
\end{abstract}

Keywords: STEM, argumentation skills, learning science.

\section{PENDAHULUAN}

Dalam pembelajaran sains, argumentasi disepakati sebagai komponen penting mengingat ilmu sains merupakan hasil konstruksi dari teori yang berisi penjelasan serta bukti yang mendukung penjelasan tersebut. Argumentasi menjadi sentral dari pendidikan khususnya dalam pendidikan sains yaitu untuk membuat makna dan memberi efek penting pada pembelajaran (Yilmaz dkk., 2017). Hal tersebut didasari oleh beberapa pendapat yang menyatakan bahwa keterlibatan siswa dalam argumentasi ilmiah dapat meningkatkan pemahaman konseptual, epistemologis, dan metodologis tentang sains (Blanchard \& Sampson, 2012), juga mendukung siswa untuk enkulturasi ke dalam praktik sains (Dawson \& Venville, 2010). Terkait hal tersebut, peningkatan kualitas pembelajaran dengan menerapkan pendidikan STEM sebagai suatu pendekatan preventif

\footnotetext{
*Corresponding author: Jurusan Kimia FMIPA Universitas Negeri Malang, Jl. Semarang No. 5 Malang Email: astridkinantya19@gmail.com

ISSN 2528-6536 (print)/ISSN 2579-5945 (online) @2019 J-PEK
} 
diharapkan mampu membantu siswa mengintegrasikan aspek Science, Technology, Engineering dan Mathematics sehingga berimbas pada peningkatan keterampilan argumentasi. Sebelumnya, pendidikan STEM telah terbukti memiliki dampak positif pada prestasi siswa (Austin, Hirstein, \& Walen, 1997; Hurley, 2001), sikap dan minat dalam pembelajaran (Tseng dkk., 2013) dan motivasi mereka untuk belajar (Gutherie dkk., 2000). Selain itu, pendidikan STEM telah dilaporkan dapat meningkatkan keterampilan berpikir tingkat tinggi siswa dan literasi teknologi, melatih kemampuan pemecahan masalah pada siswa, inovator dan penemu yang baik (Morrison, 2006; Stohlmann dkk., 2012), juga efektif untuk meningkatkan hasil belajar non-kognitif siswa seperti motivasi (Erlandson \& McVittie, 2001; Vars, 2001; Weilbacher, 2001).

Untuk mendapatkan dampak maksimal dari kemungkinan manfaat pendidikan STEM, penting untuk memastikan bahwa pengintegrasian aspek STEM dilaksanakan dengan benar (Stohlmann dkk., 2012). Oleh karena itu, dalam kajian artikel ini penulis bermaksud membahas tentang integrasi pendikan STEM dalam pembelajaran dan dampaknya untuk meningkatkan keterampilan argumentasi siswa. Pertanyaan penelitian yang memandu tinjauan awal literatur ini adalah "Bagaimana mengintegrasikan konteks STEM dalam pembelajaran untuk melatih keterampilan argumentasi dalam pembelajaran sains?".

\section{METODE}

Metodologi yang digunakan dalam penelitian ini adalah kajian literatur dengan melakukan analisis terhadap beberapa artikel. Kajian literatur dilakukan dengan mendiskusikan dan mengevaluasi penelitian sebelumnya tentang integrasi STEM dan manfaat penerapannya untuk melatih keterampilan argumentasi siswa. Rincian artikel yang dikaji tertera pada Tabel 1.

Tabel 1. Rincian Jurnal yang Dikaji

\begin{tabular}{|c|c|c|}
\hline \multicolumn{3}{|c|}{ Terkait integrasi STEM dalam pembelajaran } \\
\hline Penulis (Tahun) & Judul & Identitas Jurnal \\
\hline EL-Deghaidy, H., Mansour, N., & Context of STEM Integration in Schools: & EURASIA Journal of \\
\hline $\begin{array}{l}\text { Alzaghibi, M., \& Alhammad, K. } \\
\text { (2017). }\end{array}$ & Views from In-service Science Teachers. & $\begin{array}{l}\text { Mathematics Science and } \\
\text { Technology Education, } \\
\text { 2459-2484 }\end{array}$ \\
\hline Lucietto, Anne; Russell, Liza; Schott, & STEM Educators, How Diverse Disciplines & Journal of STEM \\
\hline Emily & Teach & $\begin{array}{l}\text { Education: Innovations } \\
\text { and Research, } 19 \text { (3) }\end{array}$ \\
\hline Lesseig, K., Nelson, T. H., Slavit, D., & Supporting Middle School Teachers' & School Science and \\
\hline \& Seidel, R. A. (2016) & Implementation of STEM Design Challenges & $\begin{array}{l}\text { Mathematics, 116(4), } \\
\text { 177-188. }\end{array}$ \\
\hline Pimthong, P., \& Williams, J. (2018) & $\begin{array}{l}\text { Preservice teachers' understanding of STEM } \\
\text { education }\end{array}$ & $\begin{array}{l}\text { Kasetsart Journal of } \\
\text { Social Sciences. }\end{array}$ \\
\hline Margot, K. C., \& Kettler, T. (2019). & $\begin{array}{l}\text { Teachers' perception of STEM integration } \\
\text { and education: a systematic literature review }\end{array}$ & $\begin{array}{l}\text { International Journal of } \\
\text { STEM Education, 6(1). }\end{array}$ \\
\hline Asghar, A. , Ellington, R. , Rice, E. , & Supporting STEM Education in Secondary & The Interdisciplinary \\
\hline Johnson, F. , \& Prime, G. M. (2012) & Science Contexts & Journal of Problem-based \\
\hline $\begin{array}{l}\text { Al Salami, M. K., Makela, C. J., \& de } \\
\text { Miranda, M. A. (2015) }\end{array}$ & $\begin{array}{l}\text { Assessing changes in teachers' attitudes } \\
\text { toward interdisciplinary STEM teaching }\end{array}$ & $\begin{array}{l}\text { Learning (IJPBL), } 6(2) \\
\text { International Journal of } \\
\text { Technology and Design } \\
\text { Education, 27(1), 63-88. }\end{array}$ \\
\hline \multicolumn{3}{|c|}{ Terkait efektivitas STEM terhadap keterampilan argumentasi } \\
\hline Penulis (Tahun) & Judul & Identitas Jurnal \\
\hline Esra Bozkurt Altan, Havva Yamak, & The Use of Design-based Learning for STEM & Universal Journal of \\
\hline , Esma Buluş Kirikkaya, Nusret & Education and Its Effectiveness on Decision & Educational Research \\
\hline Kavak (2018) & Making Skills & $6(12): 2888-2906$ \\
\hline
\end{tabular}


Lanjutan tabel...

\begin{tabular}{llll}
\hline Jeong, H., Hmelo-Silver, C. E., \& Jo, & Ten years of Computer-Supported & Educational Research \\
K. (2019) & Collaborative Learning: A meta-analysis of & Review Vol 28 \\
& CSCL in STEM education during 2005-2014 & \\
Thibaut, L., Knipprath, H., & $\begin{array}{l}\text { The influence of teachers attitudes and } \\
\text { school context on instructional practices in } \\
\text { Dehaene, W., \& Depaepe, F. (2018) }\end{array}$ & Education, 71, 190-205. \\
& integrated STEM education & \\
\hline
\end{tabular}

\section{HASIL DAN PEMBAHASAN}

\section{Argumentasi}

Argumentasi adalah aktivitas penting yang melekat dalam proses eksplorasi ilmiah (Osborne dkk., 2004). Dalam pendidikan sains, argumentasi mewakili kemampuan memilih solusi optimal dari beberapa alternatif yang ada berdasarkan bukti terhadap masalah yang tidak terstruktur, kontroversial, dan dapat diperdebatkan (Sadler, 2006). Pembelajaran sains yang efektif tidak hanya membutuhkan keterlibatan siswa aktif dalam hal penyelidikan ilmiah, tetapi juga pengembangan praktik diskursif yang memungkinkan siswa untuk menerapkan pemahaman sains mereka pada pengambilan keputusan dan terlibat dalam diskusi publik terkait isu-isu yang berkaitan dengan sains. Praktek diskursif ini meliputi evaluasi bukti, menilai validitas klaim serta menentangnya merupakan bagian dari argumentasi ilmiah (Driven dkk., 2000).

Jime'nez-Aleixandre (Jimenez-Aleixandre \& Pereiro-Munoz, 2005) mengklaim dua makna argumentasi dari perspektif individu dan sosial. Dari perspektif individu, argumentasi mengacu pada proses penalaran mengenai konstruksi kesimpulan. Dari perspektif sosial, argumentasi mengacu pada proses interaktif dalam mengelola ketidaksepakatan antara orang-orang yang berbeda pendapat. Kedua perspektif juga dikenal sebagai makna argumentasi struktural dan dialogis (McNeill \& Knight, 2013).

Dalam definisi Toulmin (1958), argumen terdiri dari unsur-unsur klaim, data, warrant, dan bukti pendukung. Dalam definisi struktural argumen ini, klaim adalah jawaban untuk pertanyaan ilmiah; bukti mungkin merupakan pengukuran dan pengamatan sehubungan dengan klaim; dan warrant atau justifikasi berfungsi sebagai penghubung antara klaim dan bukti untuk mengklarifikasi mengapa bukti spesifik mendukung klaim. Potongan-potongan ini dianggap sebagai komponen argumen. Untuk terlibat dalam argumentasi, siswa harus dapat menyatukan komponen-komponen tersebut dengan cara yang bermakna, dengan tujuan berdebat atau membujuk teman sebaya serta mengkritik argumen lain dengan cara yang mirip dengan cara yang dilakukan oleh para ilmuwan ketika terlibat dalam debat akademik (Yilmaz dkk., 2017). Terlibat dalam argumentasi dapat memperdalam pemahaman konseptual siswa karena ketika siswa mencoba membujuk orang lain, terlibat dalam organisasi pemikiran mereka, serta perbandingan dan rekonsiliasi dari berbagai pemikiran lain yang masuk akal (Wang \& Buck, 2016).

Argumen mengacu pada konten atau substansi argumentasi (Osborne dkk., 2004). Namun, sebagian besar guru tidak memiliki pengetahuan konten dan sumber daya yang diperlukan untuk merancang pembelajaran berbasis argumentasi dan memediasi lingkungan belajar untuk argumentasi. Hal ini terlihat dari diskusi kelas sebagian besar didominasi oleh monolog dari seorang guru, dengan sedikit kesempatan bagi siswa untuk terlibat dalam argumentasi dialogis (Duschl, 2007). Mengubah strategi pembelajaran untuk memacu keterampilan argumentasi siswa selama pembelajaran dan menyediakan konten yang mendukungnya dapat menjadi solusi terhadap permasalahan tersebut. Strategi yang dirancang dapat bertujuan untuk menilai apakah siswa mengintegrasikan bukti empiris untuk mendukung klaim (McNeill \& Knight, 2013); untuk mendorong siswa untuk menguraikan argumen dengan menggunakan lebih banyak bukti dan mempertimbangkan sudut pandang alternatif (Simon dkk., 2006); untuk merancang argumentasi mempelajari dengan menggunakan strategi instruksional tertentu, seperti membangun kasus yang terbuka, tidak terstruktur, atau pertanyaan yang menumbuhkan banyak sudut pandang (Berland 
\& Hammer, 2012; Berland \& McNeill, 2010; Berland \& Reiser, 2009); dan untuk menetapkan lingkungan kelas di mana siswa mendengarkan rekan-rekan mereka, berdebat, dan mempertanyakan ide-ide dalam wacana persuasif.

\section{Integrasi STEM}

Minat pendidik dalam pendidikan STEM berdasarkan pengajaran yang relevan, terfokus dan terintegrasi dari disiplin ilmu, teknologi, teknik dan matematika (Smith \& Karr-Kidwell, 2000) meningkat setiap hari. Salah satu alasan paling penting dari penerapan STEM adalah untuk meningkatkan minat individu dalam sains, teknologi, teknik dan disiplin matematika serta mendorong siswa untuk mengejar karir dalam cakupan keempat disiplin ilmu tersebut (National Research Council [NRC], 2012). Selain itu, pendidikan STEM juga menghasilkan minat pada siswa untuk mengembangkan keterampilan abad ke-21. Menurut hasil penelitian, pendidikan STEM mengembangkan minat, kesadaran karir dan sikap individu serta keterampilan abad ke-21 seperti pemikiran kreatif, kewirausahaan, komunikasi yang dalam hal ini diartikan sebagai argumentasi, juga pengambilan keputusan. Pendidikan STEM juga cocok dengan situasi masalah kehidupan nyata (Kavak dkk., 2018).

Pemahaman yang jelas tentang integrasi STEM dapat berfungsi sebagai platform yang kuat untuk secara berkelanjutan membangun kualitas yang lebih sebagai pengembangan profesional STEM. Pembahasan ini disebabkan adanya fakta bahwa meskipun para pendidik sadar akan pentingnya pendidikan STEM, pandangan guru mengenai integrasi keempat aspek dalam STEM masih kurang ( EL-Deghaidy dkk., 2017). Meskipun STEM hanya terdiri dari empat disiplin ilmu utama, STEM dapat mengambil banyak bentuk pengintegrasian, dan peneliti percaya hal tersebut secara langsung dapat mempengaruhi keputusan guru tentang strategi pengajaran yang digunakan.

Dalam studi ini, peneliti mereview beberapa artikel terkait integrasi STEM dalam pembelajaran. Kajian pertama adalah artikel oleh El-Deghaidy dkk., yang dalam penerapannya hanya mengintegrasikan dua aspek (model silo) misalnya sains dan teknologi, sains dan engineering, atau sains dan mathematic. Praktik STEM diajarkan secara terpisah sebagai 'silo' melalui pendekatan berbasis disiplin dengan koneksi terbatas ke situasi kehidupan nyata. Diketahui bahwa sains dan matematik yang dianggap paling mudah untuk diintegrasikan. Sementara itu, pengintegrasian aspek technology terbatas hanya dengan menggunakan mesin pencari internet dan integrasi engineering adalah yang paling sulit diterapkan oleh guru. Tidak ada penjelasan yang jelas bagaimana mengintegrasikan engineering dalam pembelajaran meskipun dikatakan bahwa hasil akhir yang diharapkan adalah menciptakan suatu alat.

Beberapa peneliti yang menggunakan model silo fokus secara khusus pada penggunaan konten dari sains dan matematika (misalnya Bryan, Moore, Johnson, \& Roehrig, 2015; Moore, Guzey, \& Brown, 2014), yang lain terutama menggarisbawahi pentingnya teknologi (misalnya, Kelley \& Knowles, 2016 ; Stohlmann, Moore \& Cramer, 2013). Sementara itu dilain pihak, konseptualisasi beragam didirikan dengan menganggap STEM adalah pengintegrasian keempat disiplin ilmu (Srikoom dkk., 2017). Kelompok tersebut (misalnya, O'Neill dkk., 2012; Pinnell dkk., 2013) menekankan bahwa tidak hanya penting untuk menggunakan konten dari berbagai disiplin ilmu STEM, tetapi bahwa konten ini harus terintegrasi dengan sengaja di seluruh disiplin ilmu (Srikoom dkk., 2017). Pendukung pendekatan yang lebih terintegrasi untuk pendidikan STEM juga berpendapat bahwa mengajar STEM dengan cara yang lebih terhubung, terutama dalam konteks masalah dunia nyata, dapat membuat mata pelajaran STEM lebih relevan bagi siswa dan guru. Hal ini pada gilirannya dapat meningkatkan motivasi untuk belajar dan meningkatkan minat, prestasi, dan kegigihan siswa. STEM yang mengintegrasikan keempat disiplin ilmu dipercaya juga akan meningkatkan jumlah siswa yang mempertimbangkan karier di bidang yang terkait dengan STEM (Nathan, 2014). 
Dalam praktiknya, para guru STEM harus mempersiapkan kesempatan bagi siswa untuk menerapkan integrasi konsep dan keterampilan STEM ke situasi multidisiplin yang berhubungan dengan kehidupan nyata (Pimthong \& Williams, 2018). Artikel oleh Srikoom (2017), memuat ide tentang bagaimana melakukan integrasi STEM yang bervariasi (Martín-Páez dkk., 2019) kedalam sembilan kemungkinan model pengintegrasian STEM yang mengadopsi dan memodifikasi gagasan Bybee (2013), dirangkum dari banyak diskusi, artikel, laporan, dan proyek tercantum pada Tabel 2.

Tabel 2. Perspektif Integrasi STEM menurut Bybee

\begin{tabular}{|c|c|c|}
\hline $\mathrm{No}$ & Deskripsi & Model STEM terintegrasi \\
\hline 1 & $\begin{array}{l}\text { Referensi disiplin tunggal: STEM adalah } \\
\text { pendekatan pengajaran science atau math. }\end{array}$ & \\
\hline 2 & $\begin{array}{l}\text { Science yang tergabung dengan Technology, } \\
\text { Engineering, dan/atau Math: STEM adalah } \\
\text { pengajaran pendekatan dengan science adalah } \\
\text { konsep inti dan lainnya adalah komponen minor. }\end{array}$ & \\
\hline 3 & $\begin{array}{l}\text { Sains dan Matematika terhubung oleh Technology } \\
\text { dan/atau Engineering: STEM adalah pendekatan } \\
\text { science dan math yang terhubung oleh konsep } \\
\text { technology dan engineering }\end{array}$ & \\
\hline 4 & $\begin{array}{l}\text { Empat disiplin terpisah: STEM adalah } \\
\text { pengajaran Science Technology Engineering dan } \\
\text { Math yang terpisah dan independen }\end{array}$ & \\
\hline 5 & $\begin{array}{l}\text { Sains yang tergabung dengan Teknologi, } \\
\text { Rekayasa, dan / atau Matematika: STEM adalah } \\
\text { pengajaran pendekatan yang Sains adalah konsep } \\
\text { inti dan lainnya adalah komponen minor. }\end{array}$ & \\
\hline 6 & $\begin{array}{l}\text { Menggabungkan dua atau tiga Disiplin: STEM } \\
\text { adalah pendekatan pengajaran yang paling sedikit } \\
\text { terintegrasi dua disiplin ilmu antara Sains, } \\
\text { Teknologi, Teknik, dan Matematika. }\end{array}$ & \\
\hline 7 & $\begin{array}{l}\text { Koordinasi lintas disiplin: STEM adalah } \\
\text { mengajar Teknik Teknologi Sains dan } \\
\text { Matematika secara terpisah dengan koneksi yang } \\
\text { longgar. }\end{array}$ & \\
\hline 8 & $\begin{array}{l}\text { Tumpang tindih komplementer lintas disiplin: } \\
\text { STEM adalah pendekatan pengajaran yang } \\
\text { mengajarkan sains } \\
\text { Rekayasa Teknologi dan Matematika bersama } \\
\text { oleh mengacu pada tema tertentu. }\end{array}$ & \\
\hline 9 & $\begin{array}{l}\text { Kursus atau program transdisiplin: } \\
\text { STEM merupakan pendekatan pengajaran } \\
\text { terintegrasi yang bercampur aduk } \\
\text { semua disiplin STEM secara homogen. }\end{array}$ & \\
\hline
\end{tabular}

Sumber: (Srikoom, Hanuscin, \& Faikhamta, 2017) 
Dari hasil review juga ditemui bahwa meskipun dalam pengintegrasiannya, beberapa peneliti menganggap engineering yang paling sulit diterapkan, penelitian yang dilakukan oleh Srikoom dkk., (2017) menunjukkan bahwa aspek engineering (mean $=3.16$ ) merupakan hal yang paling disoroti dalam penerapan keempat aspek STEM sementara sains menempati level terendah $($ mean $=2.69)$ seperti yang tercantum pada Tabel 3.

Tabel 3. Fokus guru terhadap pendidikan STEM

\begin{tabular}{cccccc}
\hline \multicolumn{2}{c}{ Rentang umur } & \multicolumn{4}{c}{ Tingkat fokus } \\
& & Sains & Matematika & Teknik & Teknologi \\
\hline Total 146 & Mean & 2,64 & 2,63 & 3,04 & 2,77 \\
responden & Std. Deviation & 0,93 & 0,86 & 0,85 & 0,90 \\
& & & Sumber: (Srikoom, Hanuscin, \& Faikhamta, 2017)
\end{tabular}

Hal tersebut juga sejalan dengan penelitian oleh Martín-Páez dkk., (2019) yang mendapati aspek engineering adalah yang paling dianggap penting dalam penerapan STEM (tertera pada Tabel 4).

Tabel 4. Kecenderungan intervensi disiplin STEM

\begin{tabular}{|c|c|c|}
\hline Disiplin & Frekuensi $(\%)$ & Penelitian oleh \\
\hline Sains & $4(21 \%)$ & $\begin{array}{l}\text { Beckett et al. (2016); Marle et al. (2014); Toth (2016); } \\
\text { Won, Evans, Carey, \& } \\
\text { Schnittka (2015) }\end{array}$ \\
\hline Teknologi & $3(16 \%)$ & $\begin{array}{l}\text { Caglar et al. (2015); S.-H. Chang et al. (2015); Duran et } \\
\text { al. (2014) }\end{array}$ \\
\hline Teknik & $11(58 \%)$ & $\begin{array}{l}\text { August et al. (2016); Barak and Assal (2018); English } \\
\text { et al. (2017); Evans et al. } \\
\text { (2014); Kim et al. (2015); Lamb et al. (2015); Lou et al. } \\
\text { (2017); McLurkin, } \\
\text { Rykowski, John, Kaseman, and Lynch (2013); Shahali } \\
\text { et al. (2017); Toma and } \\
\text { Greca (2018); Tseng, Chang, Lou, and Chen (2013) }\end{array}$ \\
\hline Matematika & 0 & - \\
\hline
\end{tabular}

Sumber: (Martín-Páez, Aguilera, \& Perales-Palacios, 2019)

STEM terintegrasi menawarkan siswa peluang untuk melakukan pembelajaran dalam situasi dunia nyata, dibandingkan mempelajari fragmen STEM secara terpisah (Tsupros dkk., 2009). Siswa, melalui integrasi STEM, akan:

1) Mendapatkan pemahaman yang lebih dalam dari masing-masing disiplin konsep kontekstualisasi,

2) Memperluas pemahaman tentang disiplin STEM melalui paparan konteks STEM yang relevan secara sosial dan budaya, dan

3) Meningkatkan minat dalam disiplin STEM karena saluran ditingkatkan bagi siswa untuk memasuki bidang STEM.

Dikatakan bahwa pendidikan STEM sejati membangun hubungan antara konteks akademik di mana ia diajarkan dan konteks nyata di mana kita hidup (Erdogan dkk., 2016). Biasutti dan ELDeghaidy (2014) memilih untuk mengintegrasikan antar-disiplin dari STEM agar mendapatkan dampak maksimal khususnya pemahaman konseptual yang mendalam dan mengasah keterampilan yang disebut abad ke-21.

\section{KESIMPULAN}

Salah satu upaya melatih keterampilan argumentasi adalah dengan menyediakan konten atau substansi argumentatif dalam proses pembelajaran. Pengintegrasian STEM dalam penerapan strategi pembelajaran diharapkan mampu memberi konten yang menyediakan area untuk 
berargumentasi sehingga keterampilan tersebut dapat terlatihkan. Adapun pengintegrasian STEM memiliki beragam bentuk pengintegrasian yang akan berpengaruh terhadap pemilihan strategi pembelajaran yang digunakan. Tujuan dari pembahasan beberapa model integrasi STEM dalam pembelajaran tidak untuk menunjukkan kekurangan satu dan yang lain melainkan untuk membatasi setiap pemahaman pribadi tentang pendidikan STEM dengan implikasi pada penerapannya. Dengan demikian, kebebasan untuk memahami dan menerapkan pendidikan STEM di kelas akan terbatas pada kapasitas, kebutuhan, atau kenyamanan oleh guru maupun siswa mengintegrasikan sains, teknologi, teknik, dan matematika ke dalam pembelajaran. Studi literatur juga menunjukkan bahwa siswa dapat terlibat dalam diskusi argumentatif melalui penerapan pendidikan STEM dapat mengembangkan minat, sikap serta keterampilan yang dibutuhkan pada abad 21 termasuk komunikasi yang merujuk pada keterampilan argumentasi. Dalam penerapannya, guru dapat memilih strategi yang sesuai dengan kebutuhan dan karakteristik materi. Mengenai strategi mana yang paling efektif, diperlukan pengujian empiris lebih lanjut.

\section{DAFTAR RUJUKAN}

EL-Deghaidy, H., Mansour, N., Alzaghibi, M., \& Alhammad, K. (2017). Context of STEM Integration in Schools: Views from In-service Science Teachers. EURASIA Journal of Mathematics Science and Technology Education, 2459-2484.

Berland, L. K., \& Hammer, D. (2012). Framing for Scientific Argumentation. Journal Scince Teaching, 68-94.

Blanchard, M. R., \& Sampson, V. (2012). Assessment of the Ways Students Generate Arguments in Science Scientific Argumentation: Trends in Views and Practice. Journal of Research in Science Teaching, 1122-1148.

Bybee, R. W. (2013). The case for STEM education challenges and opportunities. Washington, DC: National STEM Teachers.

Dawson, V. M., \& Venville, G. (2010). Teaching strategies for developing students' argumentation skills about socioscientific issues in high school genetics. Research in Science Education, 133-148.

Duschl, R. A. (2007). Quality argumentation and epistemic criteria. In S. Erduran \& M. P. Jime'nezAleixandre (Eds). Argumentation in science education, 159-175.

Erdogan, N., Navruz, B., Younes, R., \& Capraro, R. M. (2016). Viewing how STEM project-based learning influences students' science achievement through the implementation lens: A latent growth modeling. EURASIA Journal of Mathematics,Science \& Technology Education, 2139-2154.

Jimenez-Aleixandre, \& Pereiro-Munoz. (2005). Argument construction and change while working on a real environment problem. Argumentation in science education: Perspectives from classroom-based research, 91-115.

Kavak, N., Yamak, H., Altan, E. B., \& Kirikkaya, E. B. (2018). The Use of Design-based Learning for STEM Education and Its Effectiveness on Decision Making Skills. Universal Journal of Educational Research, 2888-2906.

Martín-Páez, T., Aguilera, D., \& Perales-Palacios, F. J. (2019). What are we talking about when we talk about STEM education? A review of literature. Wiley Science Education.

McNeill, K. L., \& Knight, A. M. (2013). Teachers' pedagogical content knowledge of scientific argumentation: The impact of professional development on k-12 teachers. . Science Education, 936972.

Nathan, M. (2014). Integration in K-12 STEM Education: Status, Prospects, and an Agenda for Research. 121st ASEE Annual Conference \& Exposition. 
National Academy of Engineering [NAE] \& National Research Council [NRC]. (2009). Engineering in K12 education understanding the status and improving the prospects. Washington: DC: National Academies Press.

National Research Council [NRC]. (2012). A Framework for k-12 science education: practices, crosscutting concepts, and core ideas. Washington DC: The National Academic.

Osborne, J. F., Erduran, S., \& Simon, S. (2004). Enhancing the quality of argumentation in school science. Journal of Research in Science Teaching, 994-1020.

Pimthong, P., \& Williams, J. (2018). Preservice teachers' understanding of STEM education. Kasetsart Journal of Social Sciences , 1-7.

Sadler, T. D. (2006). Promoting Discourse and Argumentation in Science Teacher. Journal of Science Teacher Education, 323-346.

Smith, J., \& Karr-Kidwell, P. (2000). The interdisciplinary curriculum: a literary review and a manual for administrators and teachers.

Srikoom, W., Hanuscin, D., \& Faikhamta, C. (2017). Perceptions of in-service teachers toward teaching STEM in Thailand. Asia-Pacific Forum on Science Learning and Teaching.

Stohlmann, M., Moore, T., \& Roehrig, G. (2012). Considerations for Teaching Integrated STEM Education. Journal of Pre-College Engineering Education Research, 28-34.

Toulmin, S. (1958). The uses of argument. Cambridge: Cambridge University Press.

Tsupros, N., Kohler, R., \& Hallinen, J. (2009). STEM education: A project to identify the missing components. Intermediate Unit, 11-17.

Wang, J., \& Buck, G. A. (2016). Understanding a High School Physics Teacher's Pedagogical Content Knowledge of Argumentation. J Sci Teacher Educ.

Yilmaz, Y. A., Cakiroglu, J., Ertepinar, H., \& Erduran, S. (2017). The pedagogy of Argumentation in Science Education: Science Teacher's Instructional Practices. International Journal of Science Education, 1-22.

Zohar, A., \& Nemet, F. (2002). Fostering students' knowledge and argumentation skills through dilemmas in human genetics. Journal of Research in Science Teaching, 35-62. 